\title{
Microbial contamination in herbal medicines available in Bangladesh
}

\author{
Noor $\mathrm{R}^{1}$, Huda $\mathrm{N}^{1}$, Rahman $\mathrm{F}^{1}$, Bashar $\mathrm{T}^{2}$, Munshi $\mathrm{SK}^{1}$ \\ ${ }^{1}$ Department of Microbiology, Stamford University Bangladesh, Dhaka. \\ ${ }^{2}$ Department of Pharmacology, Bangabandhu Sheikh Mujib Medical University, Dhaka. \\ Email: noor.rashed@yahoo.com
}

\begin{abstract}
Plants have long been used as herbal medicines in many countries. However, microbial contamination of these medicines may affect human health. Present study was performed to assess the pathogenic proliferation in the locally available commercial herbal oral medicines. The pathogenic load was compared with the microbiological standard given by the British Pharmacopoeia. Out of 85 oral liquid samples, 2 were found to be highly contaminated with a total aerobic bacterial load of $1.24 \times 10^{5} \mathrm{cfu} / \mathrm{ml}$, 10 samples were contaminated with fungi $\left(1.2 \times 10^{4}-6.3 \times 10^{4} \mathrm{cfu} / \mathrm{ml}\right)$. Tests for specific pathogens were carried out. One sample showed contamination by coliforms but none of the samples were contaminated by Salmonella spp. and Shigella spp. Among 40 semisolid samples, one showed to be contaminated with bacteria $\left(1.93 \times 10^{5} \mathrm{cfu} / \mathrm{g}\right)$ and 5 samples consisted of fungal load ranging between $1.5 \times 10^{4}-2.2 \times 10^{4} \mathrm{cfu} / \mathrm{g}$. The presence of bacteria and fungi in these samples thus suggest the fact that aseptic handling is necessary during processing of oral herbal medicines.
\end{abstract}

\section{Introduction}

Herbal medicines include herbs, herbal materials, herbal preparations and finished herbal products. Such medicinal preparations have been used since ancient times to treat a wide range of diseases ${ }^{1-3}$. However, the medicinal use of herbs went into a rapid decline in the Western countries when more predictable synthetic drugs were made commonly available. In contrast, many developing countries continued to get benefit from the rich knowledge of medical herbalism. For example, Ayurvedic medicine in India, Kampo medicine in Japan, traditional Chinese medicine (TCM), and Unani medicine in the Middle East and South Asia are still being used by a large majority of people ${ }^{4}$. The World Health Organization (WHO) survey indicated that about $70-80 \%$ of the world population particularly in the developing countries rely on non-conventional medicines mainly of herbal origins for their primary health care. This is because herbal medicines are relatively accessible and cheaper than the synthetic drugs 5 .

Many plants are used in traditional medications as herbal preparations for human health-care ${ }^{6}$ and they are being promoted as natural and safe without any side effects. As the use of herbal preparations by patients is increasing day by day, there is a need for pharmacists and physicians to have knowledge about the safety of these preparations ${ }^{3}$. The unscientific methods of collection, storage, transportation and congenial climatic conditions can render the raw materials for herbal drugs prone to fungal infestations. The raw materials collected using unscientific methods are commonly exposed to many pathogenic contaminants and are often deteriorated by pathogenic microorganisms before harvesting, and also during handling and storage ${ }^{6}$. Therefore, lack of regulation for herbal supplements presents potential health risk, largely their contamination chances with pathogenic microorganisms. However, only a few surveillance studies have been conducted to assess this threat ${ }^{6}$. Present study figured out the biological threats in herbal medicines and added the knowledge of proliferating bacteria, yeasts and moulds in such medicines.

Evidence of human contamination of herbs has also been reported ${ }^{7}$. Microbial contamination is assumed to occur through handling by personnel who are infected with pathogenic bacteria during harvesting/collection, post-harvest processing and the drug manufacturing process. This should be controlled by implementing best practice guidelines such as Good Manufacturing Practice (GMP) ${ }^{\mathbf{8}}$.

The microbiological quality of medicinal products became noteworthy in 1966 when over 200 cases of salmonellosis were reported from consumption of contaminated thyroid tablets, demonstrating that microbial contamination of medications can result 
in clinical infection'. Fungal contamination has been reported to affect the chemical composition of the raw materials and thereby decrease the medicinal potency of herbal drugs ${ }^{6}$. The most prominent fungal toxins reported are aflatoxins, zearalenone, ochratoxin and patulin, which are collectively known to cause hazards to the liver, nervous system, muscular system, respiratory organs as well as digestive and genital systems ${ }^{6}$. Based on this fact, we demonstrated the bacterial and fungal population in the locally available herbal medicines.

According to the WHO technical guidelines for the assessment of microbial quality of herbal preparations, determination of microbiological contaminants and limit tests for total viable aerobic bacteria and fungi indicate the quality of herbal preparations. According to the British Pharmacopoeia (2004) standards, Salmonella and Shigella species must not be present in herbal medicines intended for internal use, at any stage ${ }^{10}$. Other microorganisms should be tested and should comply with limits set in regional, national or international pharmacopoeias ${ }^{\mathbf{8}}$. Considering the total contamination chances and based on the recommended guidelines or standards, present study was designed to assess the microbiological contamination in commercial herbal oral medicines and to compare the pathogenic load with the microbiological standards for herbal preparations given by the British Pharmacopoeia. The objectives of the study were: 1) to determine the nature of microbial contamination of the herbal medicines, 2) to determine the extent of such contamination, 3) to compare the results of this study with the standards set by British Pharmacopoeia.

\section{Materials and Methods}

All materials and chemical reagents were of analytical grade. Experiments were done carefully with appropriate controls.

\section{Settings}

This cross sectional study was carried out on locally available herbal medicines from November, 2010 to November, 2011 in the Department of Microbiology, Stamford University Bangladesh.

\section{Sampling}

One hundred twenty five (125) samples of Unani and Ayurvedic preparations were collected from retailers at Sonargaon thana of Narayangonj District, Bangladesh, for assessment of their microbial contamination. Eighty five (85) oral liquid samples from 16 different batches and 40 oral semisolid products of 19 different batches were tested for microbial limits. Coliforms and two specific pathogens Salmonella spp. and Shigella spp. were checked for their presence along with the total aerobic bacterial count as well as the combined yeast and mould count. Table I shows the relevant sample codes with the number of samples of herbal oral liquids and semisolids. Samples of herbal medicines were collected in sterile glass beaker and special care was taken to prevent accidental contamination of the samples during its collection and transportation to the testing laboratory.

\section{Pre-Treatment of the Sample}

Sterile inactivating agent (Polysorbate 80) was added aseptically to the diluents (Nutrient broth) as the samples had antimicrobial activity and was mixed properly. Ten gram or $10 \mathrm{ml}$ of sample was aseptically transferred in a $150 \mathrm{ml}$ sterile conical flask. A 10-fold dilution was prepared by mixing $10 \mathrm{~g}$ or $10 \mathrm{ml}$ of sample with diluents and was mixed properly. Serial dilutions (up to $10^{-3}$ ) were made based on the expected level of microorganisms in the sample being examined.

\section{Assessment of Pathogens}

Methods prescribed in the British Pharmacopoeia (2004) were used to test microbial quality of the herbal medicines ${ }^{\mathbf{1 0}}$. In this general method, certain selective media were used. A feature common to all selective media was that the sub-lethally injured organisms could not be detected. Soybean-Casein Digest agar media were used to enumerate the total bacterial population. Sabouraud Dextrose agar (SDA) was used for the identification and enumeration of total fungi. Xylose-Lysine Deoxycholate (XLD) agar for the isolation of Salmonella spp. and Shigella spp., and MacConkey (MAC) agar media for isolation of coliforms were used. The condition of the test for microbial contamination was designed to minimize accidental contamination of the material being examined. The precautions taken during the study did not affect any microorganism ${ }^{10}$.

\section{Standard Organisms Used for Comparison Escherichia coli ATCC 8739, Salmonella typhimurium ATCC 13311, Aspergillus brasiliensis ATCC 16404 were used for the growth promotion test during the estimation of total aerobic bacterial count. They were also used as positive control during isolation and identification of coliforms, Salmonella species, yeasts and moulds. Geobacillus stearothermophilus ATCC 7953 (Spore strip) were used for the validation of autoclave sterilization.}


Total Aerobic Count (for Bacteria and Fungi)

Spread plate technique was performed for the detection of total aerobic count (bacteria, yeast \& mould). One $\mathrm{ml}$ of the treated sample from the required dilution was spread over the culture media and incubated at $35{ }^{\circ} \mathrm{C}-37{ }^{\circ} \mathrm{C}$ for 48 to 72 hours for allowing the growth of aerobic bacteria and 22 ${ }^{\circ} \mathrm{C}-25{ }^{\circ} \mathrm{C}$ for 5 to 7 days for the growth promotion of total combined yeast and mould. After incubation, the individual colonies were counted. The arithmetic averages of the counts were taken and the number of colony forming units (cfu) was calculated per gram or milliliter. Selective media were used to detect specific pathogens by streak plate method. Triplicate experiments were carried out and reproducible results were found.

\section{Identification of Coliforms, Salmonella spp. and} Shigella spp.

Enrichment was done to enhance the growth of pathogenic bacteria. Ten gram or $10 \mathrm{ml}$ of sample was aseptically transferred in a $150 \mathrm{ml}$ sterile conical flask marked with sample code. The sample was mixed with sufficient amount of lactose broth medium to make the final volume reaching to 100 $\mathrm{ml}$ and was mixed properly following incubation at $35{ }^{\circ} \mathrm{C}-37{ }^{\circ} \mathrm{C}$ for 18 to 24 hours for bacterial enrichment. One loop full of enriched sample was streaked aseptically by using a sterile inoculating loop on the surface of MacConkey agar and Xylose-Lysine Deoxycholate (XLD) agar media. The media were incubated at $35^{\circ} \mathrm{C}-37^{\circ} \mathrm{C}$ for 18 to 24 hours. Then the plates were observed for isolated characteristic colonies. The characteristic lactose fermenting pink colonies rather than nonlactose fermenter ones were detected and picked from MacConkey agar and Eosine Methylene Blue (EMB) agar was used for confirmation of coliforms. Triple Sugar Iron (TSI) agar test was also used for the biochemical identification of the isolates. The presence of coliforms was confirmed by the appearance of bluish-black colonies with green metallic sheen on EMB agar medium.

\section{Results}

Quantification of Pathogens and Comparison with the Set Standard

Out of 85 liquid samples, 2 samples showed very high bacterial load $\left(1.24 \times 10^{5} \mathrm{cfu} / \mathrm{ml}\right), 10$ samples showed high yeast \& mould $\left(1.2 \times 10^{4}-6.3 \times 10^{4}\right.$ $\mathrm{cfu} / \mathrm{ml}$ ) growth that did not comply with the given standards (tables I \& III). One sample showed contamination by coliforms which are intestinal bacteria and are indicator for contamination by feces. None of the samples showed contamination by Salmonella spp and Shigella spp. Out of 40 semisolid samples, one sample showed very high bacterial load $\left(1.93 \times 10^{5} \mathrm{cfu} / \mathrm{g}\right), 5$ samples showed high yeast \& mould $\left(1.5 \times 10^{4}-2.2 \times 10^{4} \quad \mathrm{cfu} / \mathrm{g}\right)$ growth that did not comply with the given standards (Tables II \& IV). None of the samples showed contamination by E. coli and Salmonella spp.

\section{Bacterial Pathogens in the Herbal Medicines}

As shown in Table I, sample no. 5 showed the bacterial growth at the highest dilution as too numerous to count (TNTC). Sample code SJer, sample no. one showed the total bacterial count $1.24 \times 10^{5} \mathrm{cfu} / \mathrm{ml}$ that did not comply with the given standard. In semisolid products, sample code EZam, sample no. one showed the total bacterial count of $1.93 \times 10^{5} \mathrm{cfu} / \mathrm{g}$ that did not comply with the given standard (Table II). However, others complied with the standard given by British Pharmacopoeia.

\section{Fungal Pathogens in the Herbal Medicines}

Among the liquid products, sample code SCar, sample no. $3 \& 7$ showed that the total yeast \& mould count was $2.5 \times 10^{4} \mathrm{cfu} / \mathrm{ml}$ and $1.2 \times 10^{5}$ cfu/ml; code SSaf, sample no. $3 \& 8$ showed the total count $7.7 \times 10^{4} \mathrm{cfu} / \mathrm{ml}$ and $3.6 \times 10^{4} \mathrm{cfu} / \mathrm{ml}$, respectively (table II). Code SNau, sample no. 3, 5 \& 6 consecutively showed the total count $2 \times 10^{4} \mathrm{cfu} / \mathrm{ml}$, TNTC at the highest dilution and $6.3 \times 10^{4} \mathrm{cfu} / \mathrm{ml}$; code SIct, sample no. 3 showed that the total count was $1.8 \times 10^{4} \mathrm{cfu} / \mathrm{ml}$; code $\mathrm{SFev}$, sample no. one showed the total count $1.2 \times 10^{4} \mathrm{cfu} / \mathrm{ml}$ and sample code SJer and the sample no. one consisted of $2.2 \times 10^{5} \mathrm{cfu} / \mathrm{ml}$ of total fungi (Table III), which did not comply with the given standard. Presence of pathogens could pose serious health risk as discussed later. In semisolid products, sample code MUsh, sample no. 1, 3 \& 4 consecutively showed the total yeast \& mould count $2.2 \times 10^{4} \mathrm{cfu} / \mathrm{g}, 1.7 \times 10^{4} \mathrm{cfu} / \mathrm{g}$ and $2 \times 10^{4} \mathrm{cfu} / \mathrm{g}$ (table IV). Code MMum, sample no. one showed the total count $1.5 \times 10^{4} \mathrm{cfu} / \mathrm{g}$; code EZam, sample no. one consisted of $1.5 \times 10^{4} \mathrm{cfu} / \mathrm{g}$ (Table IV) of aerobic pathogens that did not comply with the given standard of British Pharmacopoeia. All the other samples complied with the given standard.

\section{Specific Pathogens in the Herbal Medicines}

One liquid product, sample code SNau, sample no. 6 showed the presence of coliforms that did not comply with the given standard. All other samples complied with the standard for coliforms as given in British Pharmacopoeia. All of the samples were free of Salmonella spp. and Shigella spp., and hence complied with the given standard. 
Table I: Determination of total viable aerobic bacterial count in oral liquid samples

\begin{tabular}{|c|c|c|c|c|c|c|c|c|c|c|c|c|}
\hline \multirow{2}{*}{$\begin{array}{l}\text { Sl. } \\
\text { No. }\end{array}$} & \multirow{2}{*}{$\begin{array}{c}\text { Sample } \\
\text { Code }\end{array}$} & \multirow{2}{*}{$\begin{array}{c}\text { No. of } \\
\text { Samples }\end{array}$} & \multicolumn{10}{|c|}{ Total number of viable aerobic bacterial count $(\mathrm{cfu} / \mathrm{ml}$ or $\mathrm{cfu} / \mathrm{g})$} \\
\hline & & & $S-1$ & $\mathrm{~S}-2$ & $\mathrm{~S}-3$ & $\mathrm{~S}-4$ & $S-5$ & $S-6$ & $\mathrm{~S}-7$ & $\mathrm{~S}-8$ & $S-9$ & $S-10$ \\
\hline 01 & SCin & 10 & $<10$ & $1 \times 10^{2}$ & $5 \times 10^{2}$ & $1.5 \times 10^{3}$ & $1 \times 10^{2}$ & $<10$ & $1 \times 10^{2}$ & $<10$ & $5.5 \times 10^{3}$ & $4.5 \times 10^{3}$ \\
\hline 02 & Scar & 10 & $9 \times 10^{3}$ & $1 \times 10^{3}$ & $1 \times 10^{3}$ & $2 \times 10^{3}$ & $4 \times 10^{2}$ & $6 \times 10^{3}$ & $6.8 \times 10^{4}$ & $1 \times 10^{3}$ & $1 \times 10^{3}$ & $1 \times 10^{2}$ \\
\hline 03 & SSaf & 08 & $1 \times 10^{3}$ & $5 \times 10^{2}$ & $3.6 \times 10^{4}$ & $7 \times 10^{3}$ & $5 \times 10^{3}$ & $8 \times 10^{2}$ & $5 \times 10^{3}$ & $4 \times 10^{3}$ & - & - \\
\hline 04 & SAlv & 10 & $6.5 \times 10^{3}$ & $7.5 \times 10^{3}$ & $7 \times 10^{3}$ & $1.1 \times 10^{4}$ & $1.05 \times 10^{4}$ & $1.15 \times 10^{4}$ & $2.2 \times 10^{4}$ & $7.5 \times 10^{3}$ & $6.5 \times 10^{3}$ & $1.4 \times 10^{4}$ \\
\hline 05 & Salk & 10 & $1 \times 10^{2}$ & $1 \times 10^{2}$ & $1 \times 10^{2}$ & $2 \times 10^{3}$ & $1 \times 10^{2}$ & $<10$ & $1 \times 10^{2}$ & $1.96 \times 10^{4}$ & $<10$ & $3 \times 10^{2}$ \\
\hline 06 & SNau & 06 & $4 \times 10^{2}$ & $4 \times 10^{3}$ & $2.2 \times 10^{4}$ & $1 \times 10^{3}$ & *TNTC & $6 \times 10^{4}$ & - & - & - & - \\
\hline 07 & SIct & 05 & $3 \times 10^{3}$ & $8 \times 10^{3}$ & $5 \times 10^{3}$ & $3 \times 10^{3}$ & $7 \times 10^{3}$ & - & - & - & - & - \\
\hline 08 & SMar & 04 & $1.5 \times 10^{3}$ & $3 \times 10^{3}$ & $1 \times 10^{3}$ & $2 \times 10^{3}$ & - & - & - & - & - & - \\
\hline 09 & SMas & 04 & $1.5 \times 10^{3}$ & $2 \times 10^{3}$ & $1 \times 10^{3}$ & $2 \times 10^{2}$ & - & - & - & - & - & - \\
\hline 10 & SFev & 02 & $1.6 \times 10^{4}$ & $1 \times 10^{2}$ & - & - & - & - & - & - & - & - \\
\hline 11 & SJer & 02 & $* 1.24 \times 10^{5}$ & $2 \times 10^{3}$ & - & - & - & - & - & - & - & - \\
\hline 12 & SJin & 02 & $1 \times 10^{3}$ & $1 \times 10^{2}$ & - & - & - & - & - & - & - & - \\
\hline 13 & SRaf & 09 & $1 \times 10^{3}$ & $2 \times 10^{3}$ & $5 \times 10^{2}$ & $2 \times 10^{2}$ & $1 \times 10^{3}$ & $1 \times 10^{3}$ & $<10$ & $<10$ & $1 \times 10^{2}$ & - \\
\hline 14 & HBal & 01 & $7 \times 10^{3}$ & - & - & - & - & - & - & - & - & - \\
\hline 15 & Hash & 01 & $6 \times 10^{3}$ & - & - & - & - & - & - & - & - & - \\
\hline 16 & HAmr & 01 & $2 \times 10^{3}$ & - & - & - & - & - & - & - & - & - \\
\hline
\end{tabular}

All the experiments have been done three times and the results were reproducible. One representative data have been shown.

*Samples which exceed standard levels were indicated as bold. S: Sample. TNTC: Too Numerous to Count

Table II: Determination of total viable aerobic bacterial count in oral semisolid samples

\begin{tabular}{|c|c|c|c|c|c|c|c|}
\hline \multirow[t]{2}{*}{ Sl. No. } & \multirow[t]{2}{*}{ Sample Code } & \multirow[t]{2}{*}{ No. of Samples } & \multicolumn{5}{|c|}{ Total number of viable aerobic bacterial count $(\mathrm{cfu} / \mathrm{ml}$ or $\mathrm{cfu} / \mathrm{g})$} \\
\hline & & & $S-1$ & $S-2$ & $\mathrm{~S}-3$ & $\mathrm{~S}-4$ & $S-5$ \\
\hline 17 & CPra & 05 & $4 \times 10^{3}$ & $2 \times 10^{2}$ & $1 \times 10^{2}$ & $1 \times 10^{3}$ & $3 \times 10^{2}$ \\
\hline 18 & MMug & 05 & $9 \times 10^{3}$ & $1 \times 10^{4}$ & $5 \times 10^{3}$ & $1.2 \times 10^{4}$ & $1 \times 10^{3}$ \\
\hline 19 & MArd & 02 & $1 \times 10^{2}$ & $1 \times 10^{3}$ & - & - & - \\
\hline 20 & MKun & 01 & $1.2 \times 10^{3}$ & - & - & - & - \\
\hline 21 & MFal & 02 & $9 \times 10^{3}$ & $1 \times 10^{4}$ & - & - & - \\
\hline 22 & MSur & 01 & $1.2 \times 10^{4}$ & - & - & - & - \\
\hline 23 & MCho & 03 & $1.2 \times 10^{4}$ & $1.4 \times 10^{2}$ & $4 \times 10^{3}$ & - & - \\
\hline 24 & Mush & 05 & $4 \times 10^{4}$ & $1 \times 10^{4}$ & $4.2 \times 10^{4}$ & $6 \times 10^{3}$ & $2.8 \times 10^{4}$ \\
\hline 25 & MMum & 01 & $6.5 \times 10^{4}$ & - & - & - & - \\
\hline 26 & MLan & 03 & $7 \times 10^{3}$ & $2.2 \times 10^{4}$ & $1 \times 10^{3}$ & - & - \\
\hline 27 & JJar & 02 & $3 \times 10^{3}$ & $4 \times 10^{2}$ & - & - & - \\
\hline 28 & JSha & 01 & $3.8 \times 10^{4}$ & - & - & - & - \\
\hline 29 & JTam & 01 & $1.1 \times 10^{4}$ & - & - & - & - \\
\hline 30 & EUst & 02 & $4.6 \times 10^{4}$ & $2 \times 10^{3}$ & - & - & - \\
\hline 31 & ESha & 02 & $1.2 \times 10^{4}$ & $1.8 \times 10^{4}$ & - & - & - \\
\hline 32 & EBad & 01 & $1 \times 10^{3}$ & - & - & - & - \\
\hline 33 & EZam & 01 & $* 1.93 \times 10^{5}$ & - & - & - & - \\
\hline 34 & LKab & 01 & $1.6 \times 10^{4}$ & - & - & - & - \\
\hline 35 & KAbr & 01 & $3 \times 10^{3}$ & - & - & - & - \\
\hline
\end{tabular}

All the experiments have been done three times and the results were reproducible. One representative data have been shown.

*Samples which exceed standard levels were indicated as bold. S: Sample. TNTC: Too Numerous to Count

Table III: Determination of total viable fungal count in oral liquid samples

\begin{tabular}{|c|c|c|c|c|c|c|c|c|c|c|c|}
\hline \multirow{2}{*}{$\begin{array}{l}\text { Sl. } \\
\text { No. }\end{array}$} & \multirow[t]{2}{*}{ Sample Code } & \multicolumn{10}{|c|}{ Total number of viable fungal count (cfu/ml or cfu/g) } \\
\hline & & $\mathrm{S}-1$ & $\mathrm{~S}-2$ & $\mathrm{~S}-3$ & $\mathrm{~S}-4$ & $\mathrm{~S}-5$ & $S-6$ & $\mathrm{~S}-7$ & $\mathrm{~S}-8$ & $\mathrm{~S}-9$ & $\mathrm{~S}-10$ \\
\hline$\overline{01}$ & SCin & $<10$ & $<10$ & $<10$ & $<10$ & $1 \times 10^{3}$ & $2 \times 10^{3}$ & $<10$ & $1 \times 10^{3}$ & $1 \times 10^{2}$ & $1 \times 10^{2}$ \\
\hline 02 & Scar & $1.4 \times 10^{3}$ & $5 \times 10^{2}$ & $* 2.5 \times 10^{4}$ & $1 \times 10^{2}$ & $1 \times 10^{2}$ & $2 \times 10^{3}$ & $* 1.2 \times 10^{5}$ & $4 \times 10^{2}$ & $4 \times 10^{2}$ & $1 \times 10^{2}$ \\
\hline 03 & SSaf & $<10$ & $<10$ & $* 7.7 \times 10^{4}$ & $1.6 \times 10^{3}$ & $2 \times 10^{3}$ & $1.5 \times 10^{3}$ & $5 \times 10^{2}$ & $* 3.6 \times 10^{4}$ & - & - \\
\hline 04 & SAlv & $2.4 \times 10^{3}$ & $1.6 \times 10^{3}$ & $2 \times 10^{3}$ & $1.5 \times 10^{3}$ & $1.8 \times 10^{3}$ & $1.2 \times 10^{3}$ & $6 \times 10^{3}$ & $1 \times 10^{3}$ & $1.2 \times 10^{3}$ & $3 \times 10^{3}$ \\
\hline 05 & Salk & $<10$ & $1 \times 10^{3}$ & $<10$ & $1 \times 10^{2}$ & $<10$ & $<10$ & $<10$ & $<10$ & $2 \times 10^{3}$ & $<10$ \\
\hline 06 & SNau & $1 \times 10^{3}$ & $1 \times 10^{3}$ & $* 2 \times 10^{4}$ & $2 \times 10^{3}$ & *TNTC & $* 6.3 \times 10^{4}$ & - & - & - & - \\
\hline 07 & SIct & $8 \times 10^{2}$ & $2 \times 10^{3}$ & $* 1.8 \times 10^{4}$ & $6.5 \times 10^{3}$ & $2 \times 10^{3}$ & - & - & - & - & - \\
\hline 08 & SMar & $8 \times 10^{2}$ & $1 \times 10^{3}$ & $1 \times 10^{2}$ & $4 \times 10^{2}$ & - & - & - & - & - & - \\
\hline 09 & SMas & $1.2 \times 10^{3}$ & $8 \times 10^{2}$ & $1 \times 10^{3}$ & $2 \times 10^{2}$ & - & - & - & - & - & - \\
\hline 10 & SFev & $* 1.2 \times 10^{4}$ & $<10$ & - & - & - & - & - & - & - & - \\
\hline 11 & SJer & $* 2.2 \times 10^{5}$ & $6 \times 10^{3}$ & - & - & - & - & - & - & - & - \\
\hline 12 & SJin & $1 \times 10^{4}$ & $<10$ & - & - & - & - & - & - & - & - \\
\hline 13 & SRaf & $1 \times 10^{2}$ & $1 \times 10^{3}$ & $<10$ & $1 \times 10^{3}$ & $5 \times 10^{2}$ & $<10$ & $<10$ & $1 \times 10^{3}$ & $1 \times 10^{3}$ & - \\
\hline 14 & HBal & $7 \times 10^{2}$ & - & - & - & - & - & - & - & - & - \\
\hline 15 & Hash & $6 \times 10^{2}$ & - & - & - & - & - & - & - & - & - \\
\hline 16 & HAmr & $2 \times 10^{2}$ & - & - & - & - & - & - & - & - & - \\
\hline
\end{tabular}

All the experiments have been done three times and the results were reproducible. One representative data have been shown. Number of samples according to the sample code has been mentioned in Table 1.

*Samples which exceed standard levels were indicated as bold. $\quad$ S: Sample TNTC: Too Numerous to Count 
Table IV: Determination of total viable fungal count in oral semisolid samples

\begin{tabular}{ccccccc}
\hline S1. & Sample & \multicolumn{5}{c}{ Total number of viable fungal count (cfu/ml or cfu/g) } \\
No. & Code & S -1 & $\mathrm{~S}-2$ & $\mathrm{~S}-3$ & $\mathrm{~S}-4$ & $\mathrm{~S}-5$ \\
\hline 17 & CPra & $2 \times 10^{3}$ & $1 \times 10^{2}$ & $<10$ & $1 \times 10^{2}$ & $5 \times 10^{2}$ \\
18 & MMug & $3 \times 10^{3}$ & $5 \times 10^{3}$ & $1 \times 10^{3}$ & $4 \times 10^{3}$ & $1 \times 10^{2}$ \\
19 & MArd & $<10$ & $1 \times 10^{2}$ & - & - & - \\
20 & MKun & $1 \times 10^{3}$ & - & - & - & - \\
21 & MFal & $2 \times 10^{3}$ & $2.4 \times 10^{3}$ & - & - & - \\
22 & MSur & $7 \times 10^{3}$ & - & - & - & - \\
23 & MCho & $5 \times 10^{3}$ & $4 \times 10^{3}$ & $4 \times 10^{3}$ & - & - \\
24 & Mush & $* 2.2 \times 10^{4}$ & $2 \times 10^{3}$ & $* 1.7 \times 10^{4}$ & $* 2 \times 10^{4}$ & $7 \times 10^{3}$ \\
25 & MMum & $* 1.5 \times 10^{4}$ & - & - & - & - \\
26 & MLan & $4 \times 10^{3}$ & $1 \times 10^{4}$ & $1 \times 10^{2}$ & - & - \\
27 & JJar & $<10$ & $1 \times 10^{2}$ & - & - & - \\
28 & JSha & $6 \times 10^{3}$ & - & - & - & - \\
29 & JTam & $5 \times 10^{3}$ & - & - & - & - \\
30 & EUst & $5 \times 10^{3}$ & $1 \times 10^{2}$ & - & - & - \\
31 & ESha & $2 \times 10^{3}$ & $2 \times 10^{3}$ & - & - & - \\
32 & EBad & $1 \times 10^{3}$ & - & - & - & - \\
33 & EZam & $* 1.5 \times 10^{4}$ & - & - & - & - \\
34 & LKab & $1 \times 10^{4}$ & - & - & - & - \\
35 & KAbr & $<10$ & - & - & - & - \\
\hline
\end{tabular}

All the experiments have been done three times and the results were reproducible. One representative data have been shown. Number of samples according to the sample code has been mentioned in Table II.

*Samples which exceed standard levels were indicated as bold. S: Sample. TNTC: Too Numerous to Count

\section{Discussion}

In the perspective of Bangladesh, where many people rely upon the herbal medicines for medication, the assessment of pathogens in these medicines is urgently required. Based on this urge, we attempted to identify and quantify the pathogenic microorganisms in samples randomly collected from local markets.

In Bangladesh, 650 medicinal plant species have been identified to be in use with around 25 plants having high medicinal value. Recently the "Drug Administration" in Bangladesh has set a standard guideline for manufacturing herbal medicines. The regulators have also finalized the testing criteria to boost the herbal sectors but the process was slow earlier in the absence of definite testing criteria. Considering this situation, we identified and enumerated the microbial contamination in commercial herbal medicines and compared the analytical data with the microbiological standard for herbal preparations given by the British Pharmacopoeia. According to British Pharmacopoeia (2004) standards, the limits of microbial contamination are: total aerobic bacteria $10^{5} \mathrm{cfu} / \mathrm{g}$ or $\mathrm{ml}$, yeasts and moulds $10^{4} \mathrm{cfu} / \mathrm{g}$ or $\mathrm{ml}$, Enterobacteriaceae and other Gram negative organism $10^{3} \mathrm{cfu} / \mathrm{g}$ and E. coli and Salmonella should be absent ${ }^{10}$. The results obtained from this study were compared with these standards. Our data clearly demonstrated the pathological aspects of the medicines and would thus be beneficial for the general state of knowledge about the herbal medicines.

Another aspects needs to be addressed regarding the presence of microbial contaminants in the herbal products. Presence of pathogens in these medicines can reduce or even inactivate the therapeutic activity of the products. This could be a serious public health hazard causing mortality. Several fatal infectious outbreaks have been associated with the use of heavily contaminated raw materials of natural origin with pathogens. Bauer (1998) showed that the quality criteria for herbal drugs are based on a scientific definition of the raw materials. It is difficult to establish comprehensive quality criteria for herbal drugs due to 'professional secrecy' of herbalists, but in order to improve the purity and safety of the products, observation of the "basic hygiene" during preparation, standardization of some physical characteristics such as moisture content and $\mathrm{pH}$, and the assessment of microbiological contamination levels are desirable $\mathrm{e}^{11}$. Previous studies have also confirmed the presence of potential contaminants in herbal preparations. As we found, the presence of bacteria and fungi exceeding the standard limit in some of the tested samples, thus asked for the microbiological quality assessment ${ }^{12}$. Contaminants presenting serious health hazards have been reported to be Salmonella, Escherichia coli, Staphylococcus aureus, Shigella spp. and other Gram positive and Gram negative strains of bacteria ${ }^{13-17}$. In a study, Khanyile et al. (2009) found the average bacterial count $9.5 \times 10^{4} \mathrm{cfu} / \mathrm{g}$ which complied with a regulatory standard, but the average coliform count had been $5.95 \times 10^{4} \mathrm{cfu} / \mathrm{g}$ which was significantly higher than the permitted limit of $1 \times 10^{3} \mathrm{cfu} / \mathrm{g}^{2}$. Such related studies also encouraged us to carry out present study in perspective of Bangladesh.

The results in this study showed that the microbial load of the herbal products varied considerably. The samples were contaminated to varying degrees with bacteria and fungi. In case of individual product, most of them met with the given microbiological standard but few of them could not pass the entire test. A drawback of our study was that the SDA agar were incubated for 5-7 days which supposed to be more than 10 days for the growth of many pathogenic fungi. So, there was a chance that the results obtained for fungi were underestimated.

However, this study gave emphasis on the fact that manufacturers should ensure the lowest possible level of microorganisms in the raw materials, finished dosage forms and the packaging components to maintain appropriate quality, safety 
and potency of the medicines. Quality has to be built throughout the process beginning from the selection of propagating materials to the final products reaching to the consumers. Finally, based on the suggestive data previously reported and considering the contamination status as revealed from our study, we recommend that there is an urgent need for constant monitoring and control of the microbiological standards of herbal medicines available in the local markets.

\section{References}

1. World Health Organization (WHO). WHO guidelines on safety monitoring of herbal medicines in pharmacovigilance systems, 2004. (Accessed Novenber 20, 2011, at http://www.who.int/ medicinedocs/index/assoc/s7148e/s7148e.pdf).

2. Khanyile ZC, Singh N, Smith M, Shode FO, Mngomezulz S, Dewir YH. Comparative assessment of bacterial contamination in commercial herbal products of Lessertia futescens. American-Eurasian J Agric. \& Environ Sci 2009; 5(4): 494 - 499.

3. Kulkarni C, Deshpande A, More S. Assessment of microbial contamination in commercial herbal oral medicinal liquids. International Journal of Pharma Research and Development 1999; 2(9): 191-194.

4. Mosihuzzaman M, Choudhury MI. Protocols on safety, efficacy, standardization, and documentation of herbal medicine. 2008 IUPAC, Pure and Applied Chemistry 2008; 80: 2195-2230.

5. Abba D, Inabo HI, Yakubu SE, Olonitola OS. Contamination of herbal medicinal products marketed in kaduna metropolis with selected pathogenic bacteria. Afr. J. Traditional, Complementary and Alternative Medicines 2009; 6(1): 70-77.

6. Dubey NK, Kumar A, Singh P, Shukla R. Microbial contamination of raw materials: A major reason for the decline of India's share in the global herbal market. Current Science 2008; 95(6): 717-718.

7. Kineman B, Nahikian-Nelms ML, Frazier CL. A pilot investigation of the microbial contamination of herbal supplements: is there a risk for immunocompromised populations? HIV Nutrition Update 2002 7(1): 1-9.

8. World Health Organization (WHO). WHO guidelines for assessing quality of herbal medicines with reference to contaminants and residues, 2007. (Accessed 29 November, 2011, at http://www.who.int/ medicinedocs/index/assoc/s14878e/s14878e.pdf).

9. Foote JC. The Microbiological evaluation of Chamomile. A dissertation in Food and Nutrition for the Degree of Doctor of Philosophy, 2002. (Accessed 31 May, 2011, at http://etd.lib.ttu.edu/theses/ available/ etd-06272008-31295017083568/unrestricted/ 31295017083568.pdf).

10. British Pharmacopoeia Comission. Appendix XVI (A D). In: British Pharmacopoeia, Volume IV. Wielka Brytania, Medicines Commission, 2004: 331-351.

11. Bauer R. Quality criteria and standardization of phytopharmaceuticals: Can acceptable drugs standard be achieved? Drugs Information J 1998; 32: 101-110.

12. De Smet PAGM. Overview of Herbal Quality Control. Drugs Information J 1999; 33: 717-724.

13. Arias M.L, Chaves C, Alfaro D. Microbiological analysis of some herbal infusions used as medicines. Rev Biomed 1999; 10(1):1-6.

14. Erich C, Wolfgang K, Brigitte K. Microbiological Status of Commercially Available Medicinal Herbal Drugs- A screenings study. Planta Med 2001; 67: 263269.

15. Wolfgang K., Erich C, Brigitte K. Microbial contamination of medicinal plants-A review. Planta Medica 2002; 68: 5-15.

16. Adeleye IA, Okogi G, Ojo EO. Microbial contamination of herbal preparations in Lagos, Nigeria. J. Health, Population and Nutrition 2005; 23(3): 296297.

17. Okunlola A, Adewoyin AB, Odeku AO. Evaluation of pharmaceutical and microbial qualities of some herbal medicinal products in south western Nigeria. Trop. J. Pharmaceut. Res 2007; 6(1): 661-670. 